masc. flexion von porp im ags. ihren ausgang von einer nominativform * porpaz genommen haben. Eine parallele dazu bietet möglicherweise das anord., indem ,hier in ortsnamen neben dem neutr. porp ein plural porpar (vgl. Rygh, Norske Gaardsnavne, indledning s. 11; Aschw. gramm. § 386, anm. 3) auftritt. Das färöische zeigt auch einen sing. torpur $\mathrm{m}$. Dagegen ist es wol bestimmt nicht als altertümlichkeit aufzufassen, wenn im dän. seit dem 15. jh. torp öfters als commune erscheint und seinen plural als torpe oder torper bildet.

MARBURG i. $H$.

THEODOR FRINGS und ẂOLF VON UNWERTH.

\title{
ZU DEN ZWEI LAUTVERSCHIEBUNGEN.
}

Sigmund Feist sucht in der vortrefflich ausgearbeiteten abhandlung 'Die germanische und die hochdeutsche lautverschiebung u. s. w.' (oben s. 307 ff.) wahrscheinlich zu machen, dass beide lautverschiebungen durch eine völkermischung hervorgerufen seien, nämlich die erste durch die indogermanisierung desjenigen volkes, das den grundstock der germanischen stämme abgab, die zweite infolge der aufsaugung eines anderen fremden volkes, der sogenannten alpinen rasse, durch die Deutschen in Mitteleuropa. Gewiss wird die übertragung des indogermanischen auf jenes erste fremde volk sprachliche, besonders lautliche veränderungen zur folge gehabt haben, auch diesem zweiten fremden volk können wir einen einfluss auf das ihnen aufgedrängte deutsch einräumen, obgleich hier das mischungsverhältnis einem durchschlagenden einfluss auf die sprache nicht so günstig zu sein scheint wie dort. Merkwürdig, ich muss sagen unwahrscheinlich ist nur das, dass zwei fremde, auch untereinander fremde, verschiedenen rassen angehörende völker gerade denselben lautverschiebenden trieb in die.sprachentwicklung hineingetragen hätten. Die zwei lautverschiebungen sind nicht geradezu gleich, sie konnten das wol schon wegen des verschiedenen stoffes nicht sein; aber beidemal hat der trieb dieselbe richtung und dieselben angriffspunkte. Diese 
unwahrscheinlichkeit drängt mich zu der vermutung, dass die zweite lautverschiebung doch nicht der alpinen rasse zur last zu legen sei. Feist selbst hat schon einen gewichtigen einwand vorausgesehen, nämlich den, dass man bei den nachbarn derjenigen Deutschen, die hochdeutsche mundarten sprechen, nicht auch eine ähnliche verschiebung finde; er greift die Rätoromanen heraus, vermutet übrigens bei ihnen spuren einer solchen einwirkung in dem schwanken des anlautes bei grep und krep 'fels', bula und pule 'schmetterling' oder in dem auslaut von föch 'feuer', löch 'ort'. Bei den letzten zwei wortformen hat ihn wol nur die schreibung irregeleitet; denn mit den buchstaben ch ist da ein erweichter laut gemeint (ungefähr wie $c$ vor $i$ im toskanischen), nicht ein behauchter oder ein blosser reibelaut. Das wort für 'schmetterling' verstehe ich der abstammung nach nicht, und das für 'fels' dürfte eher die entgegengesetzte lautveränderung erlitten haben, sowie das sicher bei crassus, cattus, camba u.s.w. der fall ist, soweit bei den Rätoromanen vom St. Gotthard bis zum Isonzo die aussprache gras, dyat, dyamba u. ä. üblich ist; vgl. auch ital. grasso, gamba, gonfiare, gatto, gabbia und franz. gras, jambe, gonfler (aber chat, cage). So wenig wie die Rätoromanen, haben auch die anderen nachbarn der Oberdeutschen, die Slawen, vom Isonzo und der Drau bis nach Schlesien einen der deutschen lautverschiebung ähnlichen lautwandel erfahren.

Im französischen fallen bekanntlich drei lautveränderungen auf, die den meisten anderen romanischen sprachen fremd sind: ich meine die erweichung des lat. $c, g$ vor $a$ (chat, geline, lat. cattus, gallina), die verengung des $a$ in offenen silben zu einem e-laut clef, père, lat. clavis, pater) und der übergang von lat. $\bar{u}$ zu $\ddot{u}$ (une, dur, lat. una, durus). Die erweichung von $c, g$ vor $a$ hat zwar bis heute noch nicht alle französischen mundarten ergriffen, ist aber schon ungefähr eịn jahrtausend alt; dasselbe gilt für das $e$ an stelle eines lateinischen $a$; über das alter des $\ddot{u}$ aus $\bar{u}$ ist man nicht einig: viele, besonders französische gelehrte meinen, diese aussprache schon für das 9. jh. voraussetzen zu können, andere erst fǘr die zeit, wo die schreibung ou für den laut $u$ eingeführt wurde. Nun kann man beobachten, dass dieselben drei lautverändèrungen in unseren tagen sich zu widerholen anfangen. Mitten in Frank- 
reich spricht man die wörter, in denen jetzt $k, a g$ vor $a$ zu stehen kommen, mit einem merklich palatalen $k, g$ aus und die $a$ in solchen und anderen wörtern spricht man mit einer mundstellung aus, die einen dem offenen $e$ nahe stehenden laut vernehmen lässt (quatre, lat. quattior, garder von einem germanischen wort, das nhd. 'warten' lautet); und ebenda habe ich von verkäufern des blattes Le Jour diesen namen mit einem langen, hellen, sich etwas dem $\ddot{u}$ nähernden $u$ ausrufen hören. Niemand kann voraussagien, ob diese verschiebungen diesmal wider so weit führen werden wie einstens; aber wir sehen hier dieselben triebe, die - ohne völkermischung wider durchbrechen, in derselben richtung wirken und ungefähr an denselben angriffspunkten ansetzen. Die einstige völkermischúng scheint somit gewisse leibliche und seelische eigenschaften hervorgebracht zu haben, aus denen jene triebe in die sprachentwicklung ausstrahlen, triebe, die nach vielen jahrhunderten in einem teil des volkes wider ähnliche lautveränderungen durchsetżen, wie kurz nach der völkermischung und sprachübertragung.

Man erlaube mir nun, an Feist und die germanisten 1) die frage zu richten: dürfen wir nicht ebenso auch die hochdeutsche lautverschiebung erklären?

INNSBRUCK, november 1910.

TH. GARTNER.

1) [Ich benutze die gelegenheit, um zu Feist's hypothesen in der richtung stellung $\mathrm{zu}$ nehmen, dass ich seine ausführungen über sprachübertragungen als bedingung durchgreifenden lautwandels für methodisch wertvoll halte und auch die möglichkeit zugebe, die germanische und hochdeutsche lautverschiebung auf diese weise zu erklären. Mehr aber nicht. Denn es kann auch andere gründe des lautwandels geben, deren erkenntnis uns vielleicht verschlossen bleiben wird: es muss nicht jeder grösssere lautwandel auf wandlung der zusammenșetzung des volks beruhen. Schọn die eine tatsache aus der dänischen sprachgeschichte, dass seit dem 14. jh. alle postrocalischen germ.-nord. $p, t, k$ im in- und auslaut zu $b, d, g$ verschoben sind (skapa $>$ skabe, riki $>$ rige, eta $>\infty e d e$, vgl. z. b. Noreen, Pauls Grundr. $\left.I^{2}, 612\right)$, kann uns zeigen, dass Feist's weg der erklärung nicht der einzige ist, der beschritten werden muss. Denn das dänische volk hat seit dem mittelalter sicher keine grösseren störungen seiner nationalität erlitten. Ich möchte mich daher auch heute noch hinsichtlich der gründe der germanischen und hochdeutschen lautverschiebung auf ein bescheidenes non liquet beschränken. W. B.] 